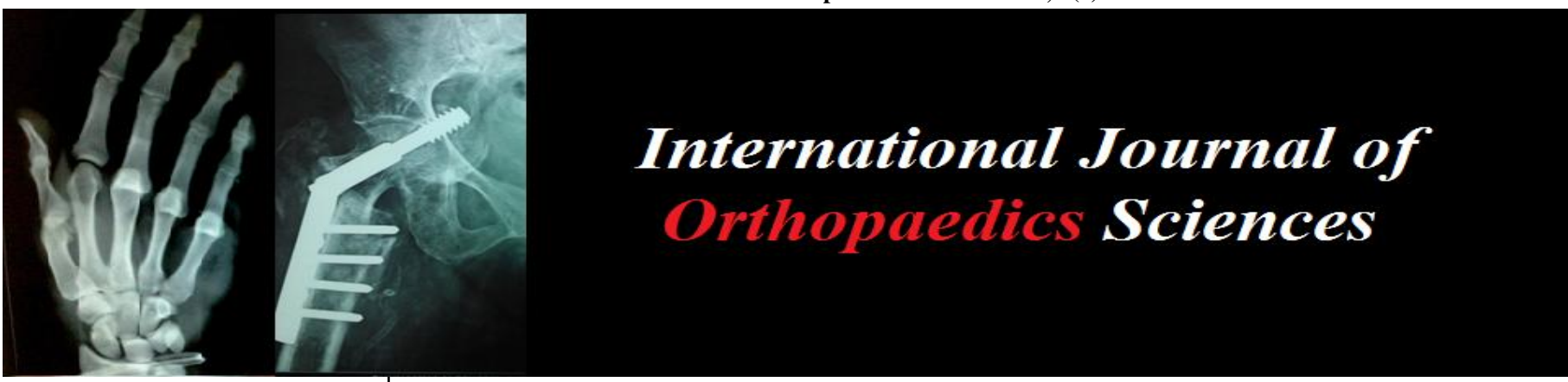

ISSN: $2395-1958$

IJOS 2017; 3(3): 1152-1156

(C) 2017 IJOS

www.orthopaper.com

Received: 07-05-2017

Accepted: 09-06-2017

Dr. Bindulal VA

D. Ortho, MS. Ortho, Assistant

Professor, Department of

Orthopaedics, Govt. T.D.

Medical College, Alappuzha,

Kerala, India

Dr. Nabeel Mohammed MS. Ortho, Senior Resident Department of Orthopaedics, Govt. T.D. Medical College, Alappuzha, Kerala, India
Correspondence Dr. Bindulal VA

D. Ortho, MS. Ortho, Assistant

Professor, Department of

Orthopaedics, Govt. T.D.

Medical College, Alappuzha,

Kerala, India

\section{Functional outcome of comminuted unstable subtrochanteric fractures treated by proximal femoral nail [PFN]}

\section{Dr. Bindulal VA and Dr. Nabeel Mohammed}

DOI: $\underline{\text { https://doi.org/10.22271/ortho.2017.v3.i3p.166 }}$

\section{Abstract}

Background: Subtrochanteric fractures are often difficult to treat and may well be associated with a mortality of more than $20 \%$. The subtrochanteric region is the site of very high mechanical stresses, the medial and posteromedial cortices were subject to high compressive forces whereas the lateral cortex experiences high tensile forces. Operative management is the treatment of choice to achieve the goals of early rehabilitation and optimal functional recovery. The purpose of the present study is to evaluate functional outcome of the subtrochanteric fractures -both high energy and low energy -treated by PFN. Functional as well as anatomical results were evaluated with regard to pain, limping, activities, deformity and range of movements. The present study was done with the hope to find out a solution for the treatment of unstable comminuted subtrochanteric fractures.

Materials and Methods: A total of 24 patients with subtrochanteric fractures presenting in the Department of Orthopaedics from August 2015 to August 2016 were treated by closed intramedullary nailing using PFN and the peroperative and postoperative complications and the functional outcome were studied. All the data was arranged in a tabulate form and analyzed using SPSS software. Chi square test was applied as a test of significance. Probability value of less than 0.05 was considered significant.

Result: Out of the 24 patients $16(66.66 \%)$ were males and $8(33.34 \%)$ were females. Most of the cases came under. Type IB (62.50\%) and Type IA (20.84\%). There were $8.3 \%$ cases each of Type II A and Type II B. In this study, 14 cases $(58.34 \%)$ were locked proximally and distally with 2 screws each. In 4 cases (16.66\%), 2 proximal screws and 1 distal screw, in 2 cases of intertrochanteric fracture, only 2 proximal screws were used. Average duration taken for union in this study was 4.5 months (Ranges from 3 months to 7.5 months). 22 (90\%) united by 6 months. There were no cases of infection. No shortening in 10 cases. Less than $1 \mathrm{~cm}$ shortening in 9 cases and $3.2 \mathrm{~cm}$ shortening in one case was found. Proximal screw penetration was noted in one case (RT type II A) at the time of 3 months follow up.

Conclusion: PFN is a safe, effective and patient friendly device useful for the treatment of all subtrochanteric fractures irrespective of their comminution. Early mobilization and rehabilitation is possible since it is a closed intramedullary procedure.

Keywords: communition, intramedullary, probability, subtrochantric

\section{Introduction}

Subtrochanteric fractures -those between the lesser trochanter and the isthmus of the femoral shaft -account for approximately 5\% to $34 \%$ of all hip fractures. In 1949, Boyd and Griffin ${ }^{[1]}$ were the first to describe subtrochanteric femur fractures and differentiate them from intertrochanteric fracture, and noted unsatisfactory postoperative results in many subtrochanteric fracture patients. According to Koch's study ${ }^{[2]}$, the value of compressive stress on medial cortex was $1100 \mathrm{~N}$, so the subtrochanteric fractures were generally comminuted fractures, due to which there was a need of reconstructing the medial cortex. Subtrochanteric fractures are often difficult to treat and may well be associated with a mortality of more than $20 \%{ }^{[3,4]}$. The subtrochanteric region is the site of very high mechanical stresses, the medial and posteromedial cortices were subject to high compressive forces whereas the lateral cortex experiences high tensile forces. This asymmetric high stress loading pattern is an important consideration in the selection of an internal fixation device and in understanding the causes of fixation failure and healing disturbances. Furthermore, the cortical bone in the subtrochanteric region is less vascular than the cancellous bone in the intertrochanteric region, therefore, the 
risk of healing complications is greater with subtrochanteric fractures than with intertrochanteric fractures. Grundy (1970)

[5] showed that the subtrochanteric area was the commonest site for femoral pathological fractures. In his study, $28.6 \%$ femoral fractures caused by Paget's disease occurred in the subtrochanteric area. Non-operative treatment of subtrochanteric fractures is rarely considered. It consists of skeletal traction followed by spica cast or cast brace. Nonoperative treatment is poorly tolerated, particularly in the elderly and multiply injured because of the need for prolonged bed rest and the potential for skin problems.

Operative management is the treatment of choice to achieve the goals of early rehabilitation and optimal functional recovery. The purpose of the present study is to evaluate functional outcome of the subtrochanteric fractures -both high energy and low energy -treated by PFN. Functional as well as anatomical results were evaluated with regard to pain, limping, activities, deformity and range of movements. The present study was done with the hope to find out a solution for the treatment of unstable comminuted subtrochanteric fractures.

\section{Materials and Methods}

A total of 24 patients with subtrochanteric fractures presenting in the Department of Orthopaedics from August 2015 to August 2016 were treated by closed intramedullary nailing using PFN and the peroperative and postoperative complications and the functional outcome were studied. A written informed consent was obtained from all the patients. All subtrochanteric fractures, Russel Taylor Type 1A, IB, IIA and IIB with fracture upto the isthmus are included in this study.

Procedure: Position of the patient supine on a fracture table. Place the contra lateral leg on a leg support. Closed reduction of the fracture done under image intensifier control. 2.5 to 3 $\mathrm{cm}$ incision made $2 \mathrm{~cm}$ above the proximal end of the greater trochanter on the extension line of the femoral axis. Cut the soft tissue sharply and deeply until the knife reaches the trochanter tip. Ream the proximal and distal fragments using $10,11,12,13,14$ reamers. Nail of at least $2 \mathrm{~mm}$ less than that of the last reamer used should be selected. Introduce the guide sleeve assembly through the jig and make a $2 \mathrm{~cm}$ incision on the lateral aspect of the thigh. Make a mark on the femur and remove the trocar. Insert a $2.8 \mathrm{~mm}$ guide wire through the drill sleeve into the bone and check both direction and position under image intensifier in AP and lateral view. Insert both distal locking screws to improve the stability. Cases were reviewed at 6 weeks intervals till fracture union and functional assessment was done using Harris Hip Score after one year.

All the data was arranged in a tabulate form and analysed using SPSS software. Chi square test was applied as a test of significance. Probability value of less than 0.05 was considered significant.

\section{Results}

Out of the 24 patients $16(66.66 \%)$ were males and 8 $(33.34 \%)$ were females. Patient age distribution ranged from 30 years to 87 years. Youngest ( 30 yrs) was a male and oldest (87 years) was a female. Peak incidence in the series was between 60-69 years (29.16\%). Average age was 54 years. Average for males was 48 years and for females 61. Out of 24 patients reviewed, $10(41.66 \%)$ had low energy injury resulting from simple falls. $6(25 \%)$ were following fall from height and $8(33.34 \%)$ due to road traffic accidents -both are high energy injuries. Graph 1 shows the classification according to Russel Taylor. Most of the cases came under. Type IB (62.50\%) and Type IA (20.84\%). There were $8.3 \%$ cases each of Type II A and Type II B. Table 1 shows stability of fixation. Stability of fixation depends on the fracture pattern, age of the patient, number of proximal screws and distal screws used. In this study, 14 cases $(58.34 \%)$ were locked proximally and distally with 2 screws each. In 4 cases (16.66\%), 2 proximal screws and 1 distal screw, in 2 cases of intertrochanteric fracture, only 2 proximal screws were used. In 4 cases $(16.66 \%)$, only one proximal screw used which is due to varus and reduction in 2 cases and too narrow neck for the insertion of 2 screws in other 2 cases. The varus malreduction cases with 1 proximal screw results in some shortening $\ll 1 \mathrm{~cm}$ ) of the affected extremity. Graph 2 shows average time duration for radiological reunion. Average duration taken for union in this study was 4.5 months (Ranges from 3 months to 7.5 months). 22 (90\%) united by 6 months. Two cases took 7.5 months for union. Table 2 shows the complications encountered during the procedure. There were no cases of infection. No shortening in 10 cases. Less than $1 \mathrm{~cm}$ shortening in 9 cases and $3.2 \mathrm{~cm}$ shortening in one case was documented. Proximal screw penetration was noted in one case (RT type II A) at the time of 3 months follow up. Screw was repositioned under regional anaesthesia. Backing out of proximal screw was noted in two cases during 3 months follow up study. Treated conservatively by delaying full weight bearing. Out of 24 cases, only one had significant malunion with varus angulation at the fracture site. This was probably due to more laterally placed entry point for the implant through the flare of the trochanter. During early postoperative period, most of the cases had moderate thigh pain, probably due to the placement of distal locking screws. Graph 3, figure 1 shows the functional results after a period of follow up. Each patient was given a numerical rating in each of these categories and the sum of the rating was used as a quantitative measure of the clinical result. These results were rated as excellent, good, fair and poor. Out of 24 cases, 15 cases $(62.5 \%)$ had excellent results, 6 cases $(25 \%)$ had good results; 2 cases $(8.33 \%)$ had fair results and 2 cases $(8.33 \%)$ had poor results.

Table 1: Stability of Fixation

\begin{tabular}{|c|c|c|}
\hline Screws used & Number of patient & Percentage \\
\hline 2 Proximal screws + 2 Distal screws & 14 & 58.34 \\
\hline 2 Proximal screws 1 Distal screw & 4 & 16.67 \\
\hline 1 Proximal screw 2 DistaL screw & 2 & 8.33 \\
\hline 1 Proximal screw 1 Distal screw & 2 & 8.33 \\
\hline 2 Proximal screw no distal screw & 2 & 8.33 \\
\hline
\end{tabular}


Table 2: Postoperative complications

\begin{tabular}{|c|c|c|}
\hline Complication & Frequency & Percentage \\
\hline Infection & 0 & 0 \\
\hline Shortening & 10 & 41.6 \\
\hline Proximal screw penetration & 1 & 4.2 \\
\hline Backing out of proximal screw & 2 & 8.3 \\
\hline Delayed union & 2 & 8.3 \\
\hline Malunion & 1 & 4.2 \\
\hline Nonunion & 0 & 0 \\
\hline Thigh pain & 20 & 83.3 \\
\hline
\end{tabular}

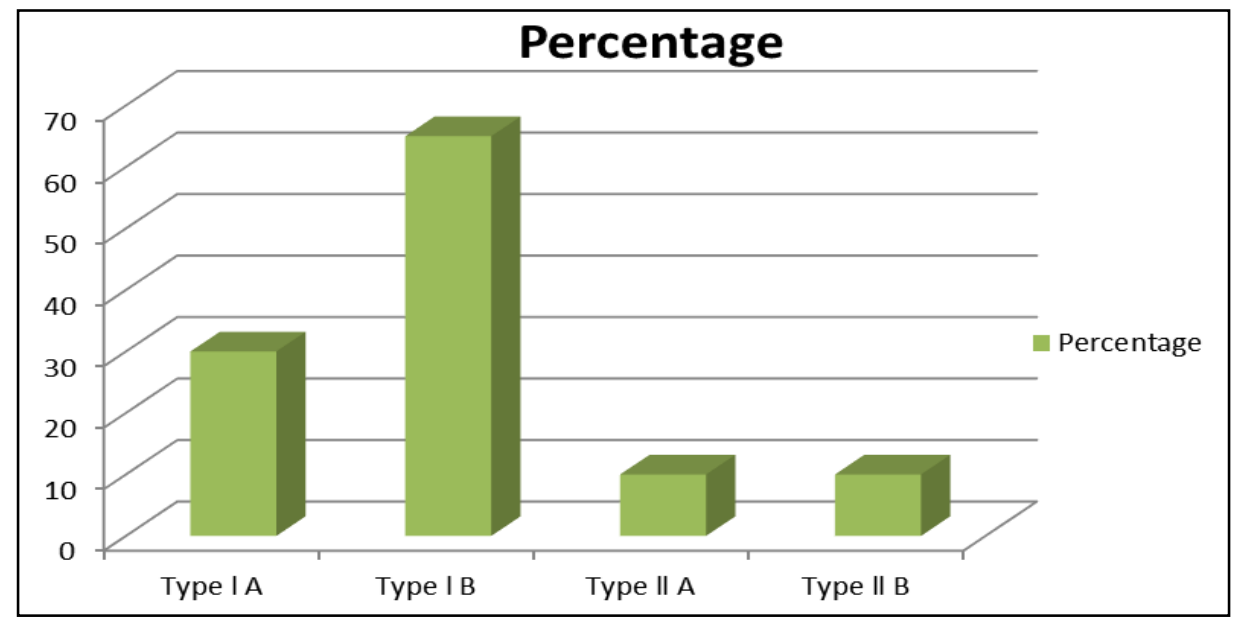

Graph 1: Russel Taylor classification

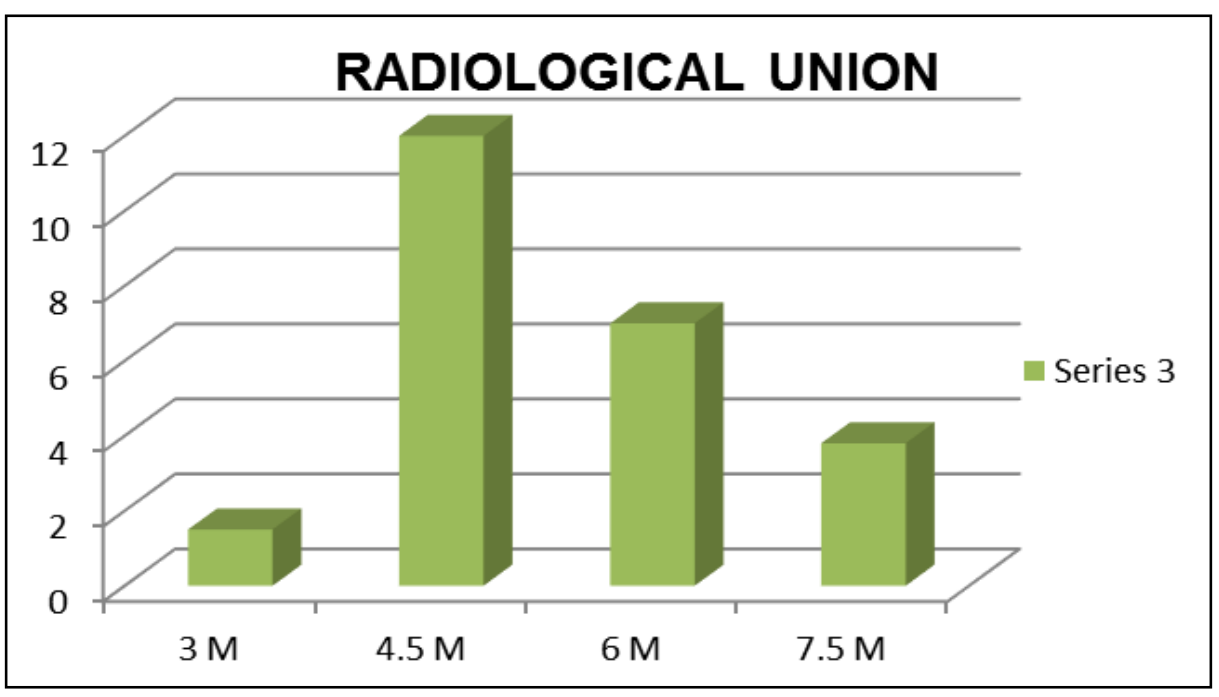

Graph 2: Time period for radiological union

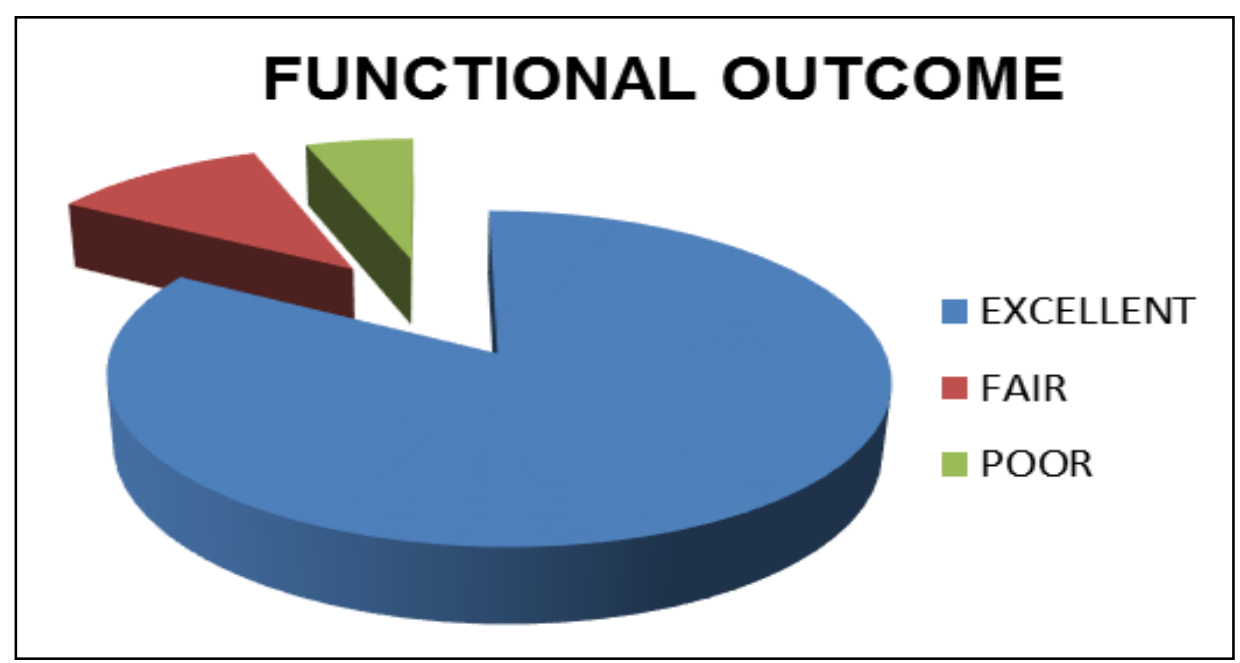

Graph 3: Functional outcome of the condition 

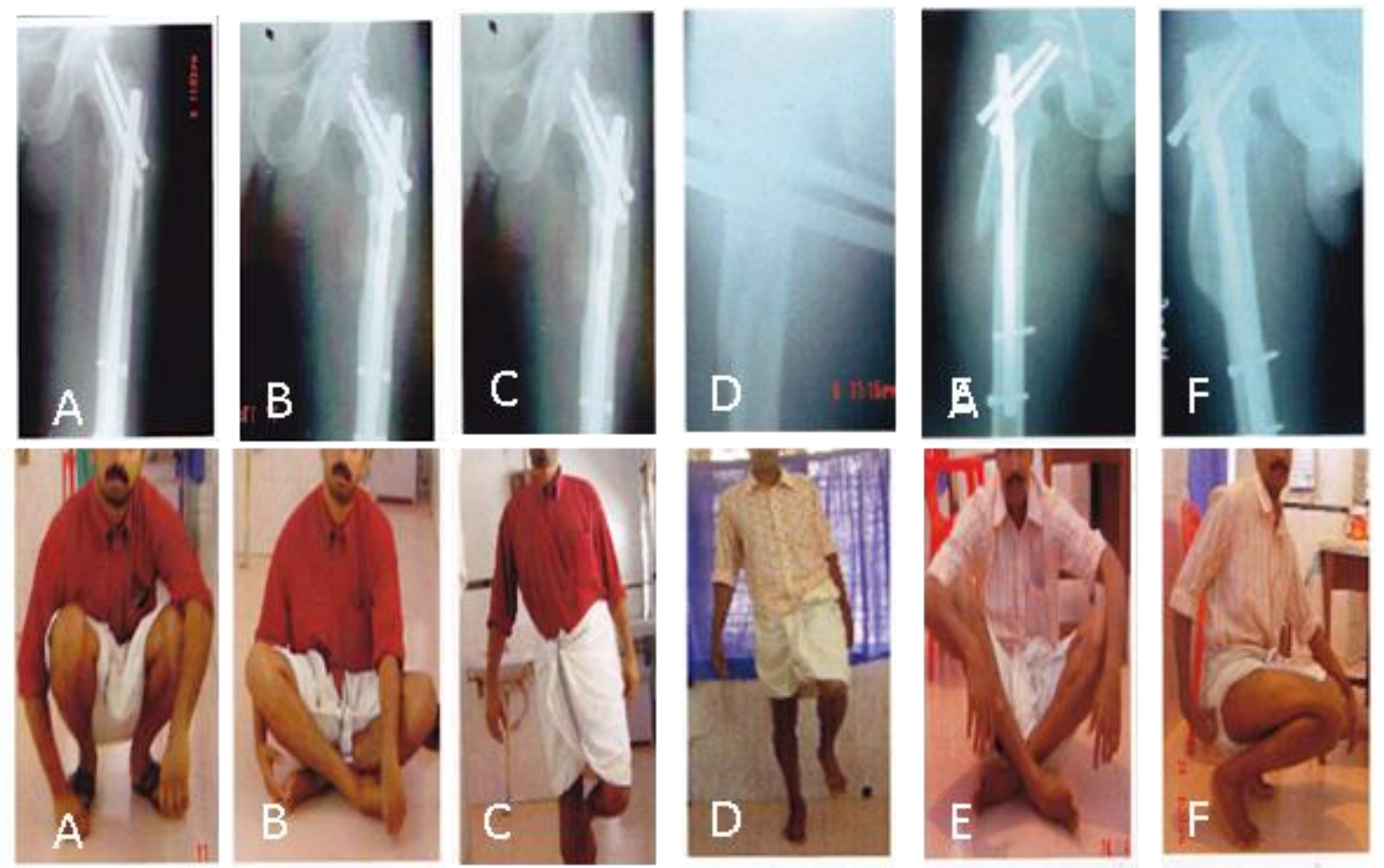

Fig 1: shows the functional outcome of two cases. A. Preop case 1 B. Post op Case 1 C. Fracture Union Case 1 D. Preop case 2 E. Post op Case 2 F. Fracture Union Case 2

\section{Discussion}

Subtronchanteric fractures are most commonly seen in the elderly, although they can occur in younger patients after high energy trauma. Parker et al. ${ }^{[6]}$ reviewed the epidermiology of subtrochanteric fractures and showed that the average age of the patients was 74 years. Average age of the patients in this study is 54 years. This is mainly due to the increase in the incidence of fractures in younger patients due to high energy trauma. The predominant injury pattern in the elderly was the simple or spiral subtrochanteric fracture with no involvement of the lesser trochanter or the piriform fossa (RT type IA). Cephalomedullary nails with a greater lateral offset al.low the entry portal to be placed more laterally so that nailing can be carried out irrespective of involvement of piriform fossa. Vlasco et al. ${ }^{[7]}$ in 1978 retrospectively analysed 82 cases of subtrochantric fracture and reported that $50 \%$ of patients who underwent conservative treatment showed unfavorable results. The proximal femoral nail (PFN) is a new intramedullary device designed by AO in 1996 which introduces the benefit of the closed technique to the treatment of subtrochanteric fractures. The PFN is made in an ultra high strength stainless steel. Muller et al. ${ }^{[8]}$ did a biomechanical analysis in 10 cadavers and compared the cerclage group with uncerclage group of subtrochantric fractures. According to the result the cerclage achieves satisfactory reduction and also maintains the integrity of the medial cortex and reduces the risk of nonunion and failure. Kim et al. ${ }^{[9]}$ managed subtrochanteric fractures with percutaneous cerclage and intramedullary fixation. In his study all fractures healed and there was no implant-related complications. In an experimental study, Gontze et al. ${ }^{[10]}$ compared the laudability of osteosynthesis of unstable per and subtrochanteric fractures and found that the PFN could bear the highest loads of all devices. Simmermacher et al. ${ }^{[11]}$ in a clinical multicenter study with 191 subtrochanteric fractures treated with PFN reported technical failures of the PFN after poor reduction, malrotation or wrong choice of screws in $5 \%$ of cases. Cut out of implant noted in one case. No mechanical failure of implant or fracture of shaft of femur at the tip of implant. In this study, $4.1 \%$ of cases had poor result and another $8.2 \%$ had fair result. All in the RT type II A \& B Subtrochanteric fractures. Screw cut out in this study was noted in two cases $(10 \%)$. Schipper IB, Steyerberg FN, Castelen RM et al. ${ }^{[12]}$ in a multicentre prospective study concluded that blood loss was lower with the PFN (220 ml Vs $287 \mathrm{ml}, \mathrm{P}=0.001)$. Postoperatively, more lateral protrusion of the hip screws of PFN (7.6\%) was documented, compared with GN (1.6\%). Most local complications were related to suboptimal reduction of the fracture and/or positioning of the implant. Functional outcome and consolidation were equal for both implants. The pitfalls and complications were mainly surgeon or fracture related rather than implant related. In the present study, backing out of proximal screw was noticed in 2 cases $(8.2 \%)$, proximal screw cut through noted in 1 case $(4.1 \%)$. Frequency of cut through of proximal screw in the literature is reported upto $10 \%$. Christophor Sadowski MD et al. ${ }^{[13]}$ in a study of 39 cases of subtrochanteric fractures, 19 cases treated with $95^{\circ}$ DCS and 20 cases with PFN concluded that att one year follow up, the rate of implant failure, the number of major reoperations were both lower for patients treated with PFN. Banan H, A1-Subti A, Jimulea T, Hart AJin ${ }^{[14]}$ reported 60 cases treated with AO/ASIF PFN. Two patients had multiple injuries; all fractures were closed. Patients followed up for a minimum of 4 months. The complication noted were 4 implant cutouts, two fractures of shaft of femur below the implant and one implant failure at 7 months due to delayed union. In a study by Sun-jun $\mathrm{Hu}$ et al., proximal lateral femur locking plate provides an effective and stable management of subtrochantric hip fractures ${ }^{[15]}$. Because of the complicated anatomy of the subtrochantric region, its management is quite challenging and even with various advancements in implant techniques, there hasn't been much reduction in complication rate ${ }^{[16]}$. According to David J. Hak et al. ${ }^{[17]}$, there are high chances of complications like malunion, delayed union and non union with implant failure while managing a case of subtrochantric fracture. Mohamed Mansour Elzohairy [18], 
Shrinand VVaidya et al. ${ }^{[19]}$ and C.Krettek et al. ${ }^{[20]}$ used dynamic condylar screw for fixation of subtrochantric fracture. He found the failure rate to be $9.7 \%$ in his study. The present study confirmed that the PFN is a useful device in the treatment of unstable, comminuted subtrochanteric fractures in younger age due to high energy trauma and spiral/oblique subtrochanteric fractures in older age due to low energy trauma. It is relatively easy procedure. PFN is a biomechanically stable construct allowing early weight bearing and rehabilitation ${ }^{[21,22]}$.

\section{Conclusion}

PFN is safe, effective and patient friendly device useful for the treatment of all subtrochanteric fractures irrespective of their comminution. Early mobilization and rehabilitation is possible since it is a closed intramedullary procedure. Weight bearing should be delayed in severely comminuted fractures. It is mandatory to place both proximal screws in the neck, along with distal locking screws for better implant stability in osteoporotic as well as severely comminuted subtrochanteric fractures.

\section{References}

1. Boyd HB, Griffin LL. Classification and treatment of trochanteric fractures. Arch Surg. 1949; 58:853e866.

2. Koch JC. The laws of bone architecture. Am J Anat. 2005; 21:177e298.

3. Manoj Kumar HV, Krishna Murthy T, Ankith NV, Somashekar D. A prospective study of clinicoradiological outcome assessment in proximal femoral fractures treated with proximal femoral nail. International Journal of Contemporary Medical Research. 2016; 3(5):1343-1346.

4. Kammar SF, Bhasme VK, Akash Hosthota, Mayur Rabhadiya. Functional outcome of proximal femur fracture managed surgically using proximal femoral nail (PFN). International Journal of Contemporary Medical Research. 2017; 4(1):22-24.

5. Grundy M. Fractures of the femur in Paget's disease of bone: Their etiology and treatment. J Bone Joint Surg. 1970; 52B:252-263,

6. Parker MJ, Dutta BK, Sivaji C, Pryor GA. Subtrochanteric fracture of the. Injury. 1997; 28:91-95.

7. Velasco RU, Comfort TH. Analysis of treatment problems in subtraochanteric fractures of the femur. $\mathbf{J}$ Trauma. 1978; 18:513e523

8. Gotze B, Bonnaire F, Weise K, Friedl H P. Belastbarkeit von Osteosynthesen bei instabilen per- und subtrochanteren Femurfrakturen: ejcperimentelle Untersuchungenmit PFN, Gamma Nagel, DHS Trochanter stabilisierungs plate $95^{\circ}$-Kondylenplatte und UFN Spiraiklinge. Aktuelie Traumatologie, 1998; 28: 197-204.

9. Simmermacher RKJ, Bosch AM, Van der Werken C. The AO/ASIF- proximal femoral nail (PFN): a new device for the treatment of unstable proximal femoral fractures. Injury. 1999; 30:327-32.

10. Muller T, Topp T, Kuhne CA, et al. The benefit of wire cerclage stabilisation of the medial hinge in intramedullary nailing for the treatment of subtrochanteric femoral fractures: a biomechanical study. Int Orthop. 2011; 35:1237e1243.

11. Kim JW, Park KC, Oh JK, et al. Percutaneous cerclage wiring followed by intramedullary nailing for subtrochanteric femoral fractures: a technical note with clinical results. Arch Orthop Trauma Surg. 2014; 134:1227e1235.

12. Schipper IB, Steyerberg EW et al. Treatment of unstable subtrochanteric fractures -Randomized comparison of Gamma Nail and PFN. JBJS. Br. 2004; 86(1):86-94.

13. Christophe Sadowski, Anne lübbeke Treatment of Reverse Oblique and Transverse Intertrochanteric Fractures with Use of an Intramedullary Nail or a $95^{\circ}$ Screw-Plate. By The Journal of Bone and Joint Surgery. 2002; 41.372.

14. Banan H, Al Sabti A, Jumulia T, Hart AJ. The treatment of unstable, extracapsular hip fractures with the AOtASIF Proximal Femoral Nail (PFN) -our first 60 cases. Injury. 2002; 33:401-405.

15. Hu S, Zhang S, Guangrong YU. The treatment of femoral subtrochanteric fractures with the proximal lateral femur locking plates. Acta Ortop Bras. 2012; 20(6):329- 33

16. de Toledo Lourenço PR, Pires RE. Subtrochanteric fractures of the femur: update. Revista Brasileira de Ortopedia, English Edition. 2016; 51(3):246-53.

17. Hak DJ, Wu H, Dou C, Mauffrey C, Stahel PF. Challenges in subtrochanteric femur fracture management. Orthopedics. 2015; 38(8):498-502.

18. Elzohairy MM. Management of Comminuted Subtrochanteric Femur Fractures by Indirect Reduction and Biological Fixation with Dynamic Condylar Screw. J Trauma Treat. 2012; 1:136

19. Vaidya Shrinand V, Devesh B, Dholakia, Anirban Chatterjee. The use of a dynamic condylar screw and biological reduction techniques for subtrochanteric femur fracture. Injury. 2003; 34.2:123-128.

20. Krettek C, Schandelmaier P, Nliclau T, Tscherne H. Minimally invasive percutaneous plate osteosynthesis (MIPPO) using the DCS in proximal and distal femoral fractures. Injury. 1997; 28:20-30.

21. Essaki Ganesan, Balaji Arumugam. Analysis of the outcome of fracture femur surgeries among adult population - a prospective study. International Journal of Contemporary Medical Research. 2016; 3(6):1723-1725.

22. Omkarnath Gudapati, Srikanth S. The management of trochanteric fractures of hip using dynamic hip screw fixation. International Journal of Contemporary Medical Research. 2016; 3(7):1946-1949. 